\title{
Smokers in the snow
}

I sit beside a window in the hospital library, down a hallway from the main desk, among the back issues of medical journals, bound and unbound, on rows of shelves. The only sound is the radiator by my feet blowing warm air up at me. This is one of my favourite places to read. Here at the margins of the clinical world, away from patients and sickness, the atmosphere is more orderly, scholarly, rational. In the books and journals on the shelves behind me, illnesses are broken down into symptoms and pathology, and patients are merged into statistics. I like to take a break here once in a while, protected by walls of evidence and certainty that resist the randomness of real medicine.

Outside the library window, it's a monochromatic February morning. Snow fell last night, and a tractor roars as it clears the sidewalk, loudly enough for the sound to penetrate into the library. Instead of reading the journal article lying open in my lap, as I had told myself I must, I am playing at being a scientist carrying on my own research project, watching the smokers outside and making observations about the process of "going for a smoke." Smoking is not permitted on hospital grounds, so everyone walks to the sidewalk where hospital property ends and the rules don't apply anymore. I know this is why they do it, but I try to imagine that I'm a researcher studying an unfamiliar culture. I think it would be puzzling to see people trudging back and forth, one after the other. After all, there's nothing about the sidewalk that's particularly suited to smoking. Maybe I would conclude it was some kind of ritual. Maybe it is.

After watching for fifteen minutes, I've decided that "going for a smoke" represents a discrete task, whereas other activities such as "walking down the street" are components of larger, more complex processes. There's a pattern. Smokers emerge from the entrance to

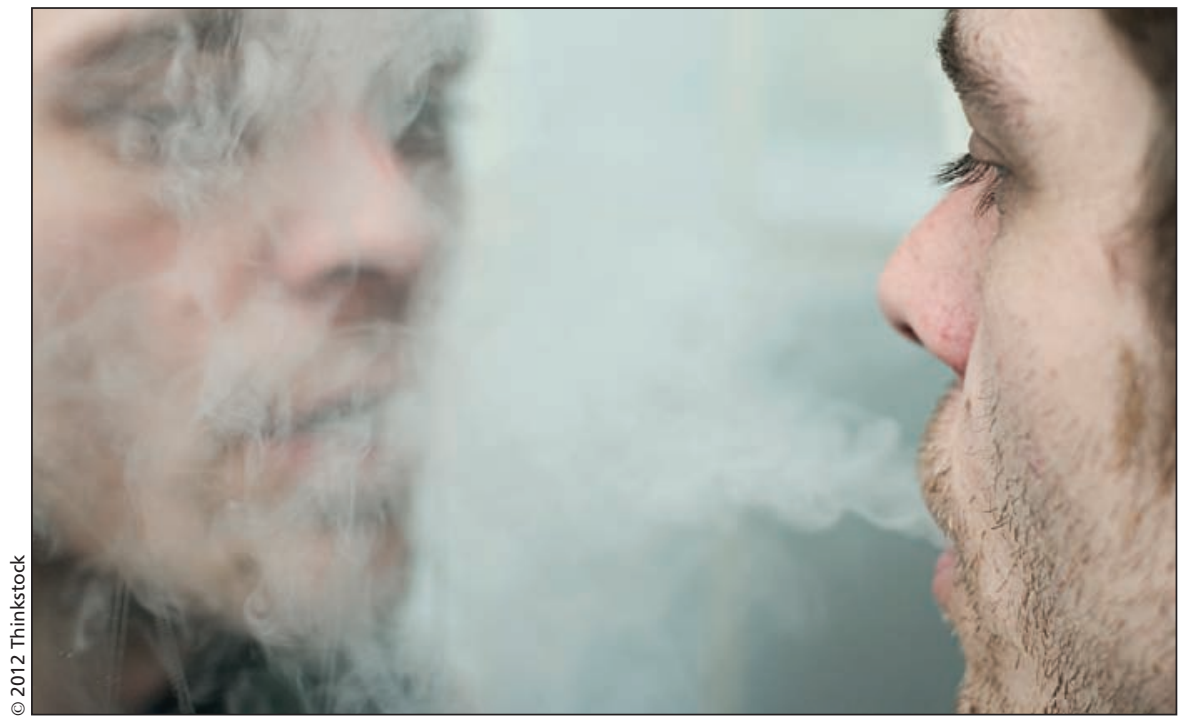

the hospital, cross the parking lot, and walk up the path to the sidewalk on the west side of the street. Some wait to reach the sidewalk before they light up, but others are impatient and don't quite make it to the legal zone. It takes less than five minutes to smoke a cigarette. Then, they retrace their steps and disappear back into the hospital.

The smokers come out singly, in pairs or, rarely, in larger groups. Many carry cups from the coffee shop in the lobby. Some set the cups down on one of the two garbage cans while they use both hands to light up. I can't see anything different about the two cans, but the one to the right of the pathway is more popular than the other to the left. Even though I have no clue why this would be, I'm pleased with myself for noticing; it seems like the kind of observation a real researcher would make.

At one point, three men come out of the hospital, cross the road and duck into a bus shelter. Five minutes later, they come out and go back into the hospital. The careful anthropological detachment I've been practising falters, and I feel annoyed. Damn smokers. Now that bus shelter will smell of second-hand smoke.
I'm surprised more of them aren't smoking in there, but maybe they do, when the weather is worse.

There's always at least one person smoking in front of the building, and five is the average. Some chat, others stand alone and smoke with determination. Patients, employees, family members: Who can tell? They look chilly, their hastily donned coats and bare hands in stark contrast with the warm gloves, hats and scarves of the pedestrians who are also using the sidewalk. Occasionally a smoker moves out of the way to allow a pedestrian past, but they never look at each other.

The smokers drop their cigarette butts and ashes on the snow, ignoring the receptacle located nearby.

I decide that if I were ever going to write up my observations, I'd take an unconventional approach. I'd claim that while medical narratives about smoking usually invoke concepts of addiction, self-destructiveness and harm, smoking beside a hospital could alternatively be seen as an act of defiance against the institution. It contradicts the dominant narrative of the hospital as a place of "healthy" activities, and of the smokers 
as participants in the "health" industry, whether as workers or patient. I could write a really thought-provoking theoretical piece arguing that smoking on the sidewalk resists oppression inherent within both the institutional policies and the value-laden efforts at "health promotion" that these policies collude with.

Then again, I wonder what reasons the smokers would give. Maybe they would just say they wanted a smoke. They're under stress, I'm sure, all of them. Someone they love is upstairs dying. They just worked a double shift, or got yelled at by their supervisor. Lots of reasons not to quit today.

I look at my watch. It's time for me to go back to work, with real people that I have to interact with and can't just observe. But I sit for one moment longer, watching as a woman in a grey coat, about my age, lights up one last cigarette. And I think, all the real action takes place at "the boundary," doesn't it? There are the smokers, crossing the line to where smoking is no longer prohibited. And here I am watching from the other side of the boundary keeps me apart from them, the glass that locks the outside out. Even when I'm not pretending to be a researcher, I still put a comfortable distance between them out there in the cold, and myself in my warm hospital. The divide that separates me, a physician and a nonsmoker, from the people who do that sort of thing; go for a smoke in the snow.

\section{Lara Hazelton MD}

Psychiatrist

Halifax, NS

CMAJ 2012. DOI:10.1503/cmaj.110482

\section{BOOKS}

\section{The life of Saint Tommy}

\author{
Tommy Douglas \\ Vincent Lam \\ Penguin Canada, Extraordinary Canadians \\ series; 2011
}

$\mathrm{T}$ he typical biographer either sharpens his subject's horns or polishes his halo. (A third option - mundane agnosticism - is rarely attempted.) Toronto emergency physician Vincent Lam reveals his choice early in Tommy Douglas: Lam's boyhood aspiration to become a physician, he explains in the first chapter, came from a desire to "... serve people irrespective of their wealth ... [and] get paid without handing any patient a bill ..."

The health care system that allows Canadian doctors to practice with such altruism is Tommy Douglas's most famous legacy, and the battle for the making of this system is Lam's passion in this book. Lam's novel, Bloodletting and Miraculous Cures won the 2006 Giller Prize. In this biography, he turns the eye of a fiction writer to the conflict between Douglas, the "poor immigrant boy whose parents had no money to pay for the specialized treatment he needed [for osteomyelitis]," and the Saskatchewan doctors who go on strike despite "a clear public mandate to proceed on medicare." This tale is told with zeal, fittingly for a David-and-Goliath story.

Unfortunately, this briskly told tale occupies only one chapter and the

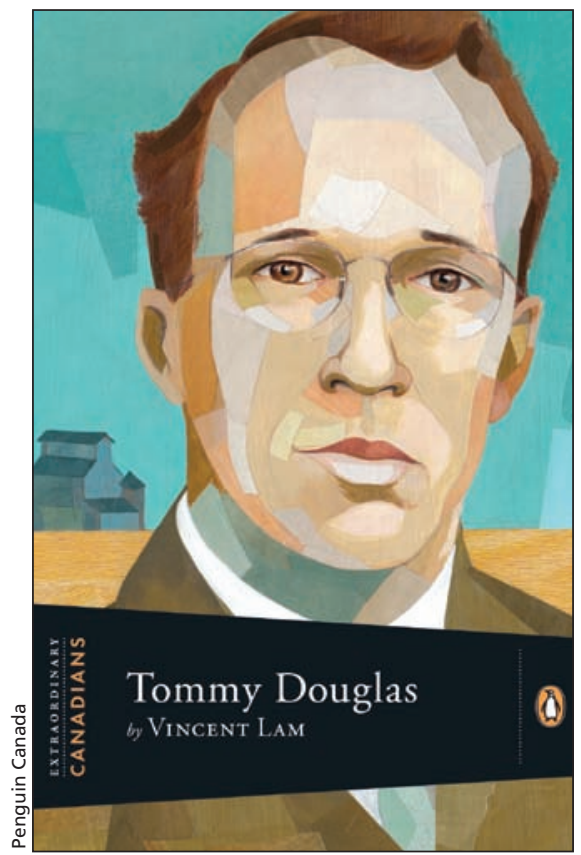

remainder of Douglas's life seems to be much less inspiring for Lam, resulting in a fairly plodding whitewash job. Douglas's tireless energy, his practical piety and his commitment to principle are demonstrated again and again. His shortcomings, on those rare occasions when they are mentioned at all, are turned to advantage: Douglas's "atrocious" French language skills, for example, permit him to be "motivated not by politics or affinity with a particular group but by a deep respect for civil rights" when he opposes the invocation of the War Measures Act during the October Crisis of 1970.
Lam is so unflinchingly reverential that his book can be taken as nothing other than hagiography. Douglas even gets in some miracles. (How else to explain that federally funded health care was enacted on a national scale, not by the socialist Cooperative Commonwealth Federation, but by Diefenbaker's Tories?) Not that this devotion need be a bad thing. Douglas is surely the patron of Canadian health care, so where is the harm in treating him as such?

What's disappointing, then, is not that Lam tries to canonize Douglas, but that he is not, on the whole, more spirited about it. After initially crediting Douglas for his life-changing decision to become a physician, Lam-thebeliever is replaced as narrator by a bland follower whose ideas are put forward as drab Sunday school rote: "To most Canadians, it has become a core part of our national ethos that health care should be equally available to all regardless of ability to pay." Where is the contemplation, the revelation? What might have been a personal and meaningful book about one man's faith in the ideas that Douglas represents is instead stale dogma.

\section{Paul Moorehead MD \\ $\mathrm{PhD}$ student \\ Pathology and Molecular Medicine \\ Queen's University \\ Kingston, Ont.}

CMAJ 2012. DOI:10.1503/cmaj.110957 